\title{
In children allergic to ragweed pollen, nasal inflammation is not influenced by monosensitization or polysensitization
}

\author{
Matteo Gelardi' \\ Mariangela Bosoni ${ }^{2}$ \\ Marco Morelli² \\ Silvia Beretta ${ }^{2}$ \\ Cristoforo Incorvaia ${ }^{3}$ \\ Serena Buttafava ${ }^{4}$ \\ Massimo Landi ${ }^{5}$ \\ Simonetta Masieri ${ }^{6}$ \\ Franco Frati ${ }^{4}$ \\ Nicola Quaranta' \\ Gian Vincenzo Zuccotti ${ }^{2}$ \\ 'Otolaryngology Section, Department \\ of Neuroscience and Sensory Organs, \\ University of Bari, ${ }^{2}$ Department \\ of Pediatrics, Luigi Sacco Hospital, \\ University of Milan, ${ }^{3}$ Allergy/ \\ Pulmonary Rehabilitation Unit, ICP \\ Hospital, ${ }^{4}$ Medical and Scientific \\ Department, Stallergenes Italy, \\ Milan, ${ }^{5}$ Department of Pediatrics, \\ ASL TOI, Turin, ${ }^{6}$ Department of \\ Otorhinolaryngology, Sapienza \\ University of Rome, Rome, Italy
}

Correspondence: F Frati Medical and Scientific Department, Stallergenes Italy, Via Tibullo 2,

20I5I Milan, Italy

Tel +393355285619

Fax +3927005 8783

Email ffrati@stallergenes.com
This article was published in the following Dove Press journal:

Journal of Inflammation Research

5 April 2016

Number of times this article has been viewed

Background: In patients polysensitized to pollen allergens, the priming effect, by which the sensitivity of the nasal mucosa to an allergen is increased by the previous exposure to another allergen, is a known phenomenon. This study was aimed at evaluating the degree of nasal inflammation, assessed by nasal cytology, in children with allergic rhinitis (AR) from ragweed pollen according to being monosensitized or polysensitized.

Methods: The study included 47 children. Of them, 24 suffered from AR caused by sensitization to grass pollen and ragweed pollen (group A) and 23 were sensitized only to ragweed pollen (group B). In all patients, the severity of AR was assessed according to the Allergic Rhinitis and Its Impact on Asthma guidelines, and comorbidities were also evaluated.

Results: In group A, $16.7 \%$ of children had a mild intermittent AR, $4.2 \%$ a moderate-to-severe intermittent, $33.3 \%$ a mild persistent, and $45.8 \%$ a moderate-to-severe persistent; in group B, $26.1 \%$ of children had a mild intermittent AR, $0 \%$ a moderate-to-severe intermittent, $52.2 \%$ a mild persistent, and $21.7 \%$ a moderate-to-severe persistent. No significant difference was detected in the number of the considered comorbidities between the two groups. The cell counts of neutrophils, eosinophils, lymphocytes/plasma cells, and mast cells were high but not significantly different in the two groups.

Conclusion: These findings show that the degree of nasal inflammation found in children with ragweed-induced AR is not influenced by additional allergy to grass pollen and confirm the previously reported absence of priming effect in ragweed allergy.

Keywords: allergic rhinitis, pollen sensitization, priming effect, nasal cytology, eosinophils, neutrophils

\section{Introduction}

Ragweed pollen is a major cause of respiratory allergy. In the pioneering age of allergy in the 19th century, when Blackley discovered that grass pollen was the cause of hay fever, Wyman demonstrated that the so-called autumnal catarrh (hay fever) was due to ragweed pollen. ${ }^{1}$ Ragweed has optimal characteristics to cause allergy because its pollen is able to induce respiratory allergy starting from concentrations as low as five to ten pollen grains per cubic meter of air and because each plant (as demonstrated for Ambrosia artemisiifolia) can produce up to 60,000 seeds, which can germinate even after lying up to 40 years in the ground. ${ }^{2}$ For a long time, ragweed allergy was apparently confined to northern America, ${ }^{3}$ but in the last few decades, a worldwide diffusion of this plant occurred. In Europe, the four species of ragweed, A. artemisiifolia (short ragweed), Ambrosia trifida (giant ragweed), Ambrosia coronopifolia (perennial ragweed), and Ambrosia tenuifolia (slimleaf bur ragweed), were accidentally introduced 
to Europe, where previously only Ambrosia maritima was known. ${ }^{4}$ Ragweed allergy was first detected in the Lyon region in France, ${ }^{5}$ followed by northern Italy, Austria, and Hungary, ${ }^{6}$ and more recently, Switzerland. ${ }^{7}$ In Italy, a spreading of this allergy also to central regions was found, mainly caused by long distance transport of pollen. ${ }^{8}$ These aspects make ragweed allergy an individual and social burden in Italy, which needs effective treatments. In this study, we aimed to evaluate the degree of nasal inflammation, assessed by nasal cytology, in children with allergic rhinitis (AR) from ragweed pollen according to being monosensitized or polysensitized, ie, sensitized also to grass pollen.

\section{Methods}

\section{Patients}

The population of this study was 47 children. Their demographic data and kind of sensitization are reported in Table 1. Oral informed consent was obtained by both parents before entering the study, and the study was conducted in accordance with good clinical practice guidelines. Allergic sensitization was evaluated by skin prick tests performed by allergen extracts from Stallergenes (Antony, France) using a complete panel of inhalant allergens, which included for grasses Dactylis glomerata, Phleum pratense, Anthoxanthum odoratum, Poa pratensis, and Lolium perenne. To be included in the study, the patients must not have any other positive tests in addition to those for grass and ragweed pollen. The symptomatic periods in the area where patients live are from April to June for grass pollen and from late August to early October for ragweed pollen. All patients were allowed to use antihistamines as needed to treat their symptoms, while corticosteroids were not permitted to avoid interference with nasal cytology. The severity of AR was assessed according to the Allergic Rhinitis and Its Impact on Asthma (ARIA) guidelines, ${ }^{9}$ and comorbidities were also evaluated. The local ethical committee, Luigi Sacco Hospital, Milan, Italy, after being informed about the procedures to be carried out gave the authorization to perform the study. Parents or legal guardians gave their written informed consent allowing the inclusion of children in the study.

Table I Demographic data and kind of sensitization in the two groups of patients

\begin{tabular}{|c|c|c|}
\hline $\begin{array}{l}\text { Patients } \\
\text { characteristics }\end{array}$ & Group A & Group B \\
\hline Sex (male/female) & $9 / 15$ & $10 / 13$ \\
\hline Mean age (years) & $10.2 \pm 3.2$ & $9.7 \pm 3.5$ \\
\hline Sensitization & $\begin{array}{l}\text { Grass pollen and } \\
\text { ragweed pollen }\end{array}$ & Ragweed pollen \\
\hline
\end{tabular}

\section{Nasal cytology}

In all study subjects, nasal cytology was performed by anterior rhinoscopy using a nasal speculum and adequate lighting. The cytological sampling consists of collecting the nasal mucosa surface cells by scraping from the middle portion of the inferior turbinate using a Rhino-probe ${ }^{\mathrm{TM}}$ (Arlington Scientific, Springville, UT, USA). When the sampling is obtained, the material is placed on a glass slide, fixed by air drying, and stained using the May-Grünwald-Giemsa method, which allows the detection of all the cellular components of the nasal mucosa, including those cells that are associated with the immune inflammation process (such as neutrophils, eosinophils, lymphocytes/plasma cells, and mast cells). The slide is then observed through a light microscope supplied with an object-glass, able to magnify up to $\times 1,000$. For the rhinocytogram analysis, at least 50 microscopic fields have to be read in order to detect all the cells present in the sample. ${ }^{10}$ The sampling was performed in all subjects in mid-May and mid-September, which are periods corresponding to the peak of symptoms from grass pollen and ragweed pollen, respectively, in Italy. In the same time periods, the total nasal symptom score as reported by Ford et al $^{11}$ was calculated for each patient by the sum of four individual scores, nasal congestion, nasal itching, rhinorrhea, and sneezing, in which each symptom was scored on a scale of $0-3$.

\section{Statistical analysis}

The comparison between the two groups of patients for the variables of the continuous type was performed by means of Student's $t$-test by calculating the $95 \%$ confidence interval. In the case of nonhomogeneity of the variances of the two groups, the nonparametric Mann-Whitney $U$ test was used. The analysis of discrete or nominal parameters was performed using the Fisher's exact test or the chi-square test. A $P$-value of at least $<0.05$ was considered significant.

\section{Results}

Twenty-four children were allergic to grass pollen and ragweed pollen and formed group A, while 23 were allergic only to ragweed pollen and formed group B (Table 1). The distribution of the clinical forms according to ARIA classification was as follows: in group A, four (16.7\%) children had a mild intermittent $\mathrm{AR}$, one (4.2\%) a moderate-to-severe intermittent, eight (33.3\%) a mild persistent, and eleven $(45.8 \%)$ a moderate-to-severe persistent; in group B, six $(26.1 \%)$ children had a mild intermittent AR, zero $(0 \%)$ a moderateto-severe intermittent, $12(52.2 \%)$ a mild persistent, and five $(21.7 \%)$ a moderate-to-severe persistent. None of these differences were statistically significant. Asthma was present 
Table 2 Comorbidities in group A and group B

\begin{tabular}{lll}
\hline Comorbidity & $\begin{array}{l}\text { Group A } \\
\text { (ragweed and } \\
\text { grass pollen), n (\%) }\end{array}$ & $\begin{array}{l}\text { Group B } \\
\text { (only ragweed), }\end{array}$ \\
\hline Sinusitis & $\mathrm{I}(4.2)$ & $\mathrm{I}(4.3)$ \\
Polyposis & 0 & 0 \\
Adenoid hypertrophy & $\mathrm{I}(4.2)$ & $3(\mathrm{I} 3)$ \\
Turbinate hypertrophy & 0 & $\mathrm{I}(4.3)$ \\
Persistent cough & 0 & $\mathrm{I}(4.3)$ \\
Dermatitis & $\mathrm{I}(4.2)$ & $\mathrm{I}(4.3)$ \\
ASA sensitivity & 0 & 0 \\
Drug allergy & $\mathrm{I}(4.2)$ & 0 \\
Food allergy & 0 & 0 \\
\hline
\end{tabular}

Abbreviation: ASA, acetylsalicylic acid.

in $25 \%$ of subjects in group A and in $30.4 \%$ of subjects in group B. The number of the considered comorbidities in the two groups is reported in Table 2. No significant difference was detected. The mean total nasal symptom score was $8.5 \pm 4.7$ in patients allergic only to ragweed and $8.0 \pm 5.2$ in patients allergic to both grass and ragweed pollen. The cell counts of neutrophils, eosinophils, lymphocytes/plasma cells, and mast cells, as assessed by nasal cytology, were high but not significantly different in subjects of group A and group B (Figure 1). Figure 2 shows a typical rhinocytogram obtained in patients with ragweed pollen allergy.

\section{Discussion}

Pollen allergy is a very common form of immunoglobulin E (IgE)-mediated hypersensitivity. The process of sensitization takes place when during seasonal exposure the antigenic proteins contained in pollen grains come into contact with antigen-presenting cells, which present them to $\mathrm{T}$ and $\mathrm{B}$ lymphocytes, with subsequent production of

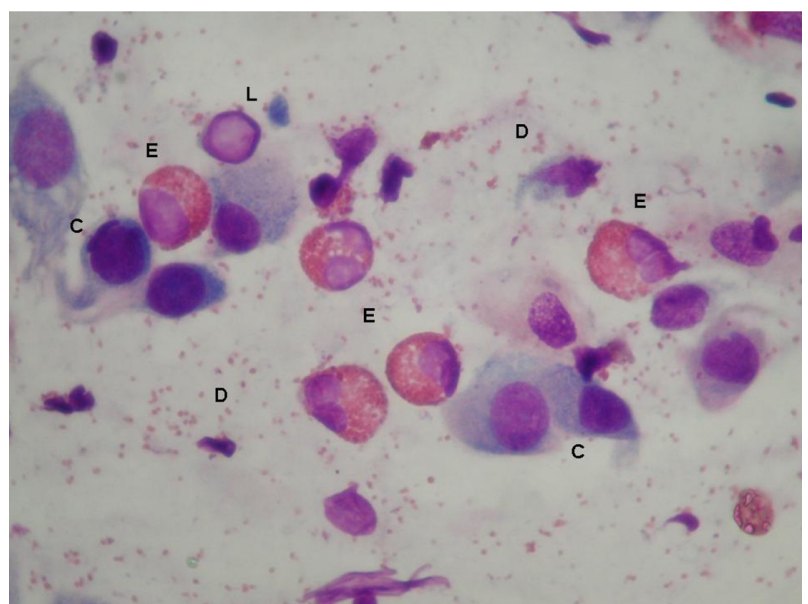

Figure 2 Nasal cytology shows eosinophils (E) with abundant degranulation (D), lymphocytes (L), and epithelial cells (C), stained by the May-Grunwald-Giemsa method with a magnification of $\times 1,000$.

specific antibodies. In atopic subjects, the prevalence of a Th2 cytokine pattern results in an IgE response. ${ }^{12}$ Then, the $\mathrm{Fc}$ portion of IgE antibodies binds to the high-affinity receptors on the surface of mast cells, and when subsequent exposure to the same allergens occurs, the cross-linking of two or more IgE molecules elicits degranulation of mast cells with release of mediators and development of clinical symptoms. This corresponds to the early phase of the allergic reaction, but the ensuing recruitment of inflammatory cells results in a late-phase reaction that sustains the ongoing symptomatology. A phenomenon occurring in the initial phases of pollen allergy is the priming effect, by which the sensitivity of the nasal mucosa makes possible that a much reduced dose of allergen can elicit a full response. ${ }^{13}$ In patients allergic to grass pollen undergoing a nasal challenge with orchard (D. glomerata) before the pollen season,

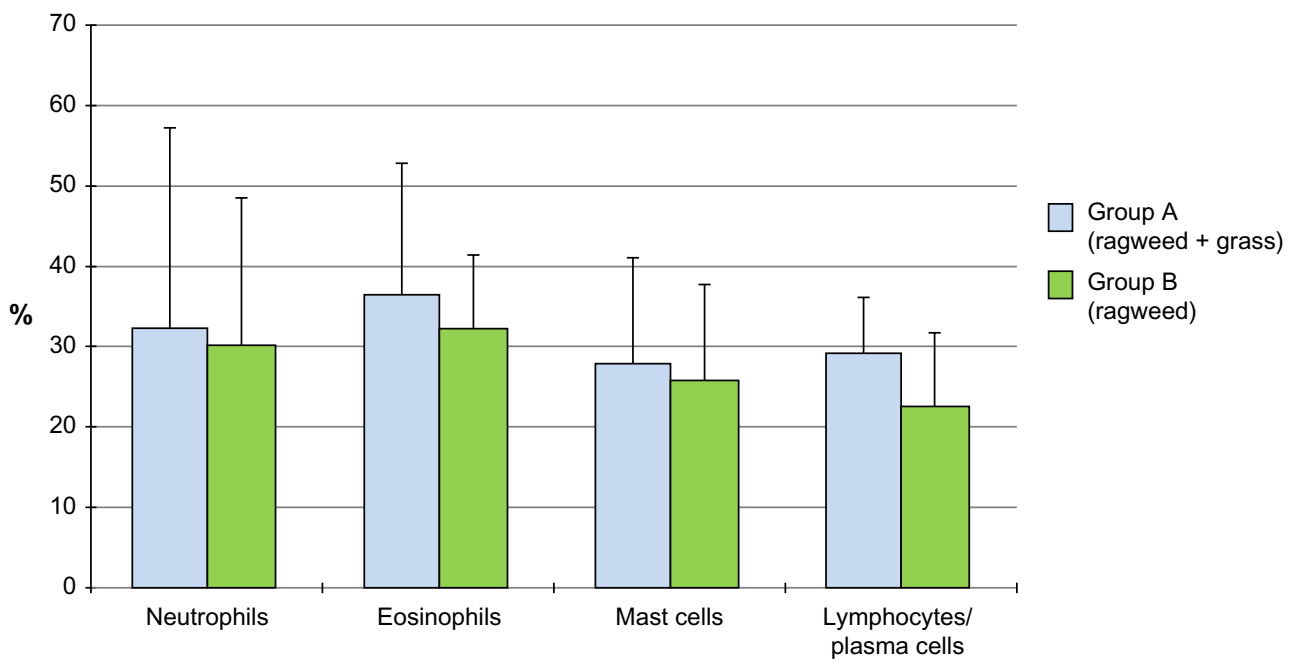

Figure I Cell count, as percentage of the total white cells (mean \pm standard deviation). 
Bousquet et al showed that subjects polysensitized also to other pollens, such as cypress, olive, and Parietaria, had symptoms occurring earlier than subjects monosensitized to grass pollen, this confirming the priming effect. ${ }^{14}$ Of interest, in the same years, it was reported that a priming effect was apparently absent in ragweed-allergic patients, as showed by similar symptom scores in early and late seasonal periods of ragweed pollination, but the patients were allergic only to ragweed. ${ }^{15}$ In this study, we compared the degree of inflammation, as evaluated by nasal cytology, in two groups of children monosensitized to ragweed pollen or sensitized to grass pollen and ragweed pollen, that have different pollination periods, with no other sensitization to inhalant allergens. Nasal cytology is a useful tool to evaluate AR, and a study demonstrated that the ARIA classification of AR severity is associated with different patterns of inflammatory cells, because patients with moderate-to-severe AR have an increased number of mast cells/lymphocytes, while the intermittent or persistent nature of the disease does not influence the cytological pattern. ${ }^{16}$ We chose to limit the study to children to avoid influence on nasal inflammation by factors other than allergy, particularly cigarette smoking. Concerning the main objective of the study, we found an abundant presence of inflammatory cells, but no significant difference was detected in their number, including neutrophils, eosinophils, mast cells, and lymphocytes/ plasma cells, comparing children allergic only to ragweed and allergic to grass pollen and ragweed. The high cell counts in both groups of children may have made it difficult to achieve a statistical significance, but still show that ragweed allergy alone elicits a grade of inflammation similar to double allergy to ragweed and grass pollen. These findings do not disprove the existence of the priming effect in ragweed allergy, but they may suggest that it is not as robust as previously found for other pollens. On the other hand, ragweed pollen contains nicotinamide adenine dinucleotide phosphate (NADPH) oxidase that induces reactive oxygen species in mucosal cells independent of adaptive immunity, facilitating antigen-induced allergic inflammation. ${ }^{17}$ In the biology of plants, intrinsic pollen NADPH oxidases are required to generate reactive oxygen species and induce pollen-tube growth. ${ }^{18}$ In addition, the climatic changes associated with the so-called global warming may cooperate, having being reported that ragweed plants grown in $\mathrm{CO}_{2}^{-}$ enriched environments produced more allergenic pollens. ${ }^{19}$ Such factors are likely to result in a higher inflammation induced by ragweed pollen, as confirmed by our data.

\section{Conclusion}

The findings from this study suggest that the nasal inflammation in children with ragweed-induced AR is not influenced by additional allergy to grass pollen. This confirm the previously reported absence of priming effect in ragweed allergy. Therefore, ragweed pollen is able to elicit by itself a strong inflammatory response in allergic patients. This suggests to manage this allergy by treatments not limited to symptomatic action but instead addressing the cause of inflammation, such as allergen-specific immunotherapy.

\section{Disclosure}

F Frati and S Buttafava are employees of Stallergenes Italia Srl. C Incorvaia is a scientific consultant for Stallergenes Italia Srl. The other authors have no conflicts of interest that are directly relevant to the content of the study.

\section{References}

1. Kay AB. Landmarks in allergy during the 19th century. Chem Immunol Allergy. 2014;100:21-26.

2. Basset I, Crompton CW. The biology of canadian weeds. 11 . Ambrosia artemisiifolia L. and A. psilostachya DC. Can J Plant Sci. 1975;55:463-476.

3. Girsh LS. Ragweed pollen distribution in the USA: utilization of graphic maps. Ann Allergy. 1982;49:23-28.

4. Tutin T. Flora Europaea. Vol. 1-5. Cambridge: Cambridge University Press; 1964-1980.

5. Touraine R, Cornillon J, de Poumeyrol B. Allergy to Ambrosia pollen in the Lyon region. Rev Fr Allergol. 1965;5:82-94.

6. D'Amato G, Spieksma FT, Liccardi G, et al. Pollen-related allergy in Europe. Allergy. 1998;53:567-578.

7. Taramarcaz P, Lambelet B, Clot B, Keimer C, Hauser C. Ragweed (Ambrosia) progression and its health risk: will Switzerland resist this invasion? Swiss Med Wkly. 2005;135:538-548.

8. Cecchi L, Morabito M, Domeneghetti PM, Crisci A, Onorari M, Orlandini S. Long distance transport of ragweed pollen as a potential cause of allergy in central Italy. Ann Allergy Asthma Immunol. 2006;96:86-89.

9. Bousquet J, van Cauwenberge P, Khaltaev N, ARIA Workshop Group; World Health Organization. Allergic rhinitis and its impact on asthma. J Allergy Clin Immunol. 2001;108(suppl 5):147-334.

10. Gelardi M, Incorvaia C, Fiorella ML, et al; Italian Academy of Nasal Cytology. The clinical stage of allergic rhinitis is correlated to inflammation as detected by nasal cytology. Inflamm Allergy Drug Targets. 2011;10:472-476.

11. Ford LB, Matz J, Hankinson T, Prillaman B, Georges G. A comparison of fluticasone propionate nasal spray and cetirizine in ragweed fall seasonal allergic rhinitis. Allergy Asthma Proc. 2015;36:313-319.

12. Parikh A, Scadding GK. Seasonal allergy. BMJ. 1997;314:1292-1295.

13. Bousquet J, Vignola AM, Campbell AM, Michel FB. Pathophysiology of allergic rhinitis. Int Arch Allergy Immunol. 1996;110:207-218.

14. Bousquet J, Hejjaoui A, Becker WM, Michel FB. Clinical and immunologic reactivity of patients allergic to grass pollens and to multiple pollen species. I. Clinical and immunologic characteristics. J Allergy Clin Immunol. 1991;87:737-746.

15. Grammer L, Wiggins C, Shaughnessy MA, Chmiel J. Absence of nasal priming as measured by rhinitis symptoms scores of ragweed allergic patients during seasonal exposure to ragweed pollen. Allergy Proc. 1990;11:243-246. 
16. Gelardi M, Incorvaia C, Passalacqua G, Quaranta N, Frati F. The classification of allergic rhinitis and its cytological correlate. Allergy. 2011;66:1624-1625.

17. Boldogh I, Bacsi A, Choudhury B. ROS generated by pollen NADPH oxidase provide a signal that augments antigen-induced allergic airway inflammation. J Clin Invest. 2005;115:2169-2179.
18. Dharajiya N, Boldogh I, Cardenas V, Sur S. Role of pollen NAD(P)H oxidase in allergic inflammation. Curr Opin Allergy Clin Immunol. 2008;8:57-62.

19. Wayne P, Foster S, Connolly J, Bazzaz F, Epstein P. Production of allergenic pollen by ragweed (Ambrosia artemisiifolia L.) is increased in CO2-enriched atmospheres. Ann Allergy Asthma Immunol. 2002;88:279-282.

\section{Publish your work in this journal}

The Journal of Inflammation Research is an international, peer-reviewed open-access journal that welcomes laboratory and clinical findings on the molecular basis, cell biology and pharmacology of inflammation including original research, reviews, symposium reports, hypothesis formation and commentaries on: acute/chronic inflammation; mediators of inflamma-
Dovepress

tion; cellular processes; molecular mechanisms; pharmacology and novel anti-inflammatory drugs; clinical conditions involving inflammation. The manuscript management system is completely online and includes a very quick and fair peer-review system. Visit http://www.dovepress.com/ testimonials.php to read real quotes from published authors.

\footnotetext{
Submit your manuscript here: http://www.dovepress.com/journal-of-inflammation-research-journal
} 